\title{
TEMPERATURE DISTRIBUTION IN THIN WALLED HEAT-EXCHANGERS HAVING NON- CIRCULAR FLOW PASSAGES
}

By

W. S. Farmer

\section{LEGAL NOTICE}

This report was prepared as an account of Government sponsored work. Neither the United States, nor the Commission, nor any person acting on behalf of the Commission:

A. Makes any warranty or representation, express or implied, with respect to the accuracy, completeness, or usefulness of the information contained in this report, or that the use of any information, apparatus, method, or process disclosed in this report may not infringe privately owned rights; or

B. Assumes any liabilities with respect to the use of, or for damages resulting from the we of any information, apparatus, method, or process disclosed in this report.

As used in the above, "person acting on behalf of the Commission" includes any employee or contractor of the Commission to the extent that such employee or contractor prepares, handles or distributes, or provides accese to, ony information pursuant to his employment or contract with the Commission.

October 23, 1951

Oak Ridge National Laboratory

Oak Ridge, Tennessee

Technical Information Service Extension, Oak Ridge, Tenn.

Photostat Price $\$ 3.30$
Microfilm Price $\$ 2.40$
Available from the
Office of Technical Services
Department of Commerce
Washington 25, D.C.




\section{DISCLAIMER}

This report was prepared as an account of work sponsored by an agency of the United States Government. Neither the United States Government nor any agency Thereof, nor any of their employees, makes any warranty, express or implied, or assumes any legal liability or responsibility for the accuracy, completeness, or usefulness of any information, apparatus, product, or process disclosed, or represents that its use would not infringe privately owned rights. Reference herein to any specific commercial product, process, or service by trade name, trademark, manufacturer, or otherwise does not necessarily constitute or imply its endorsement, recommendation, or favoring by the United States Government or any agency thereof. The views and opinions of authors expressed herein do not necessarily state or reflect those of the United States Government or any agency thereof. 


\section{DISCLAIMER}

Portions of this document may be illegible in electronic image products. Images are produced from the best available original document. 


\section{SUMAEI}

In heat exchangers, in which the walls are heated by internal

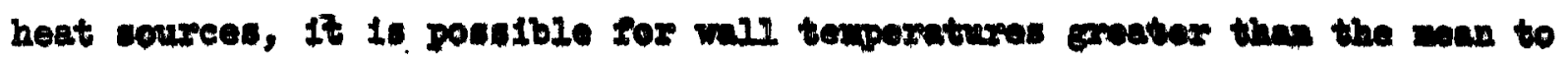

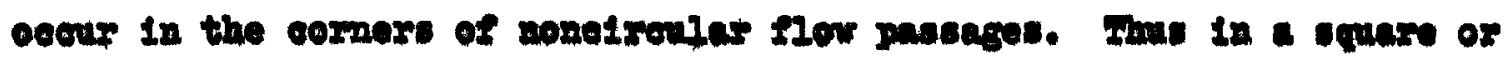

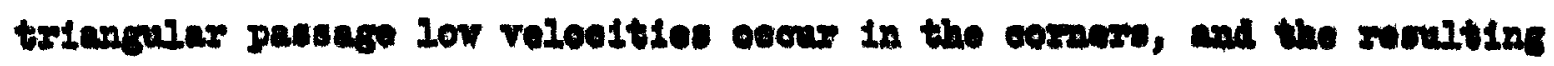

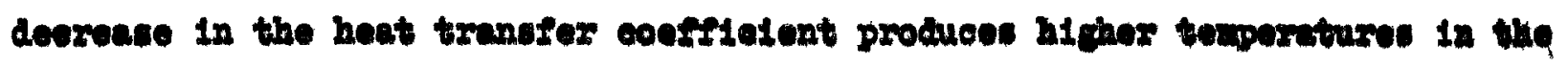
valls at these looations

\footnotetext{
A genoralized analyols is prosedted, taking into coeount the variation in the hent tranter coeffiolent alons the ourfece, by whin it is ponstble to

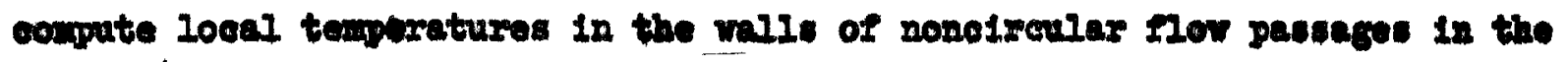
vicinity of the corners. Computations have been made for a representative component (Figure I) composed of a honey comb of rectangular passages. The resulting temperature at the hottest point is approximately $125^{\circ} \mathrm{F}$ greater than the uniform plate temperature. This analysis is based on a $90^{\circ}$ angle between the plate and retaining plate, and a uniform source distribution throughout all plates. Had the angle between the primary plate and retaining plate been much less than $90^{\circ}$ on both sides, then the resulting local temperature rise would be several times the above value. If the primary plate and retaining plate are "dead" at junctions and corners then of course a "hot spot" will not occur at these locations.
} 


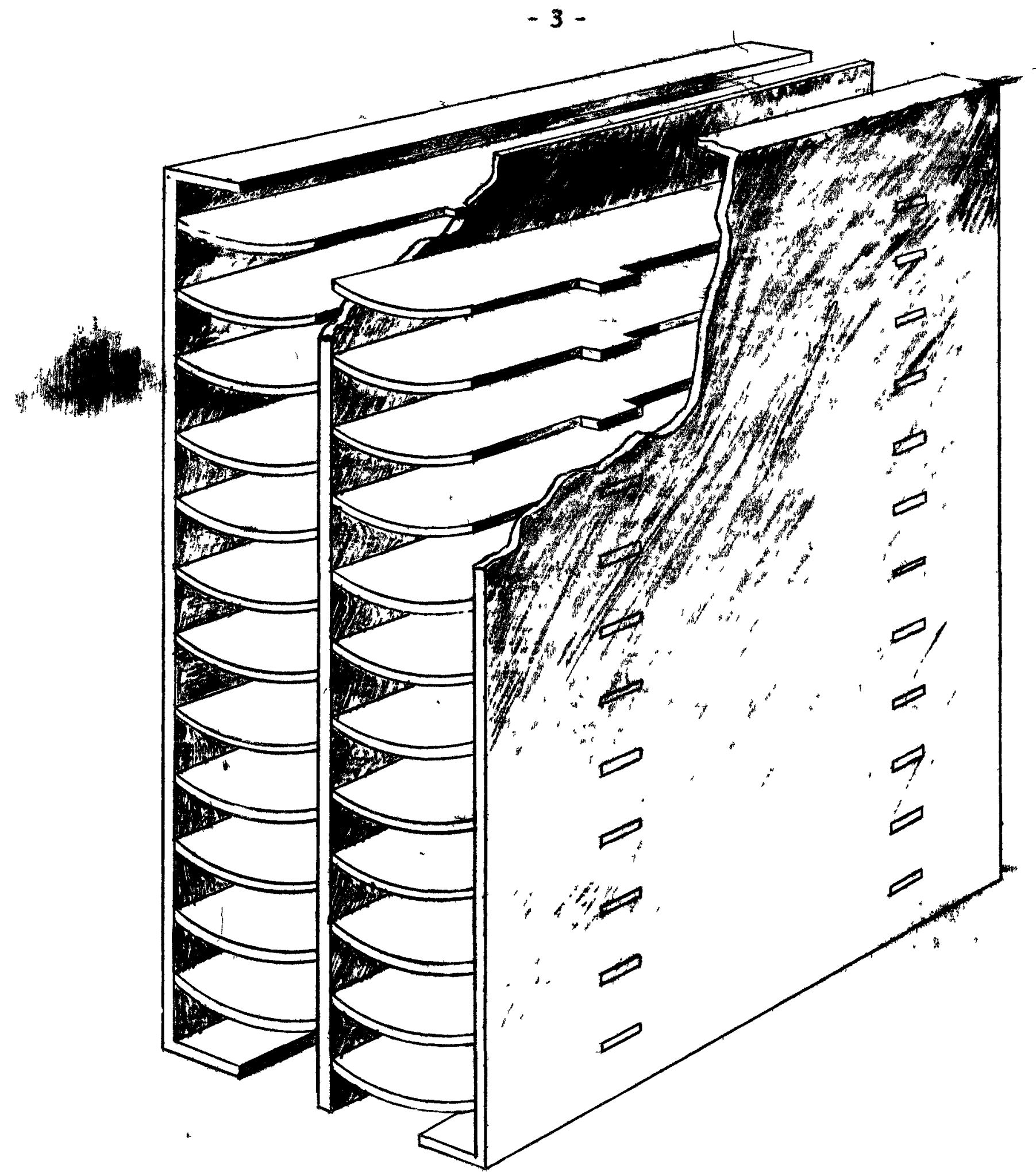

Figure I

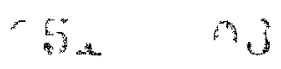

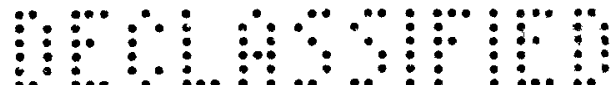




\section{ASSUMPPIONS}

A generalized analysis of this problem has been made without imposing Ilmitations on the nature of the fluid euployed. Hovever, to obtain mumerieal results a knowledge of the loeal velocity or temperature profile throughout the nonelreular passage is required.

Thus in obtaining the generalized solution the following essumgtions are made in order to obtain an amalytical result.

(1) The plate forms a fin of infinite length in the direetion of fluid motion and of uniform thickness.

(2) The thermal conduetivity of the wall is constant over the range of temperatures present in the plate and is assumed infinite across the thickess. This reduees the analysis to one dimension.

(3) The internal heat souree in the wall is assumed to be unfformly distributed throughout the wall material.

(4) The heat transfer coefficient in the corner of the passage must be capable of being approximated as a linear function of the distance from the cormer.

In order to solve the generalized equations for the particular conditions involved in the assembly, additional assumptions had to be made.

(1) The PrandtI number of the coolant is taken as 1. A condition fulfilled by air.

(2) A fully developed velocity profile is assued.

(3) The turbulent diffusivity of heat and momentum are equal. 
If these latter assumptions are fulfilled, then one can employ data for local heat transfer coefficients in noncircular flow passages. It can be seen by examining Figure 7 on page 32 of their report that the local heat transfer coefficient can be approximated by a linear function of the distance from the corner, thus satisfying a previous assumption.

\section{GENERALIZED SOLUTION}

Iet us consider one wall of a rectangular passage. The temperature of the wall will be symetrical about a plane midway between the two corners or a half width of the wall, $e$. The wall or plate $f$ in has a shape as shown below.

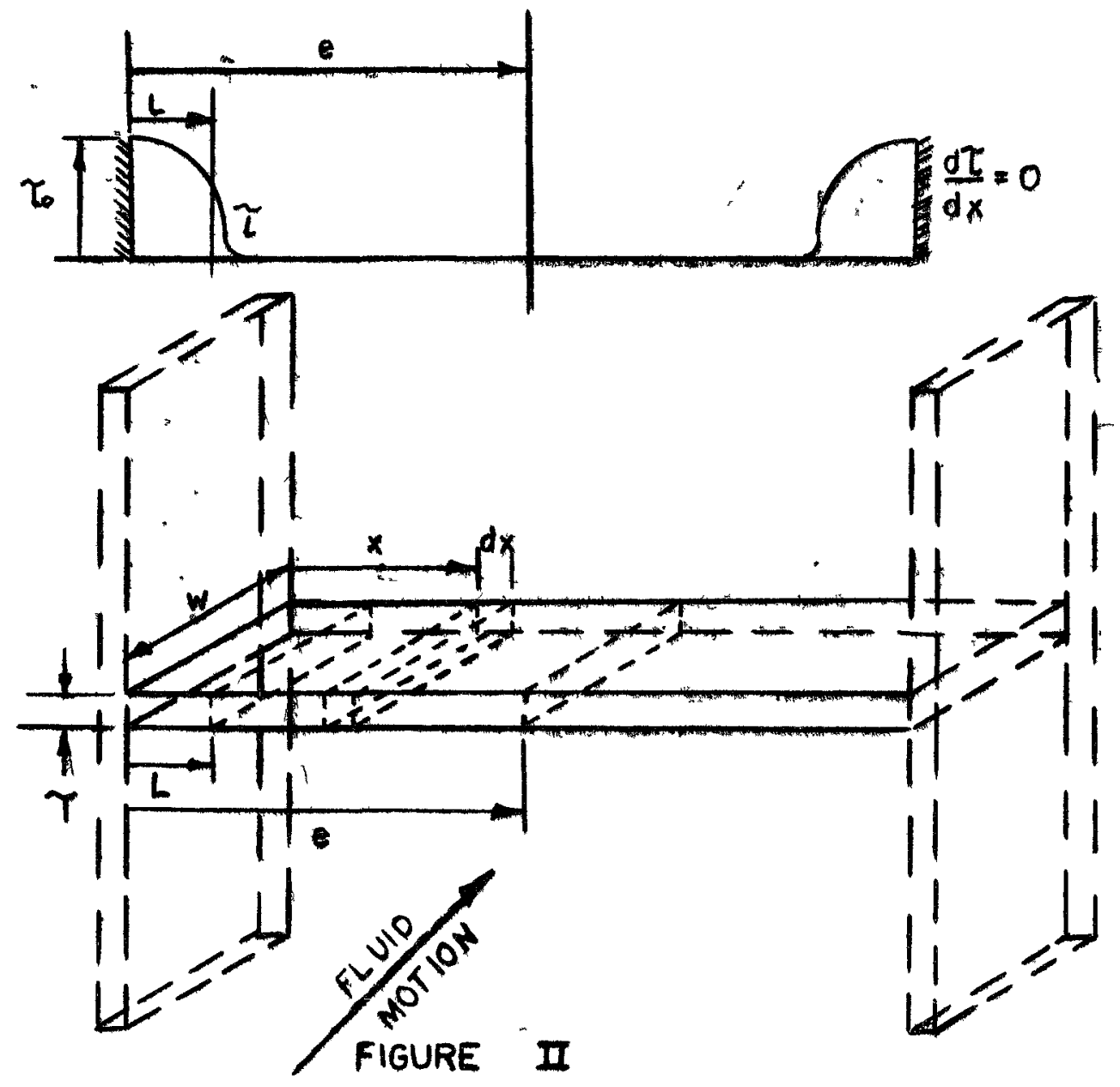

TWO REgION FIN WITH A VARIAELE HEAT TRANSFER COEFFICIENT OH THE SURFACE OF THE CORNER REGION 
where

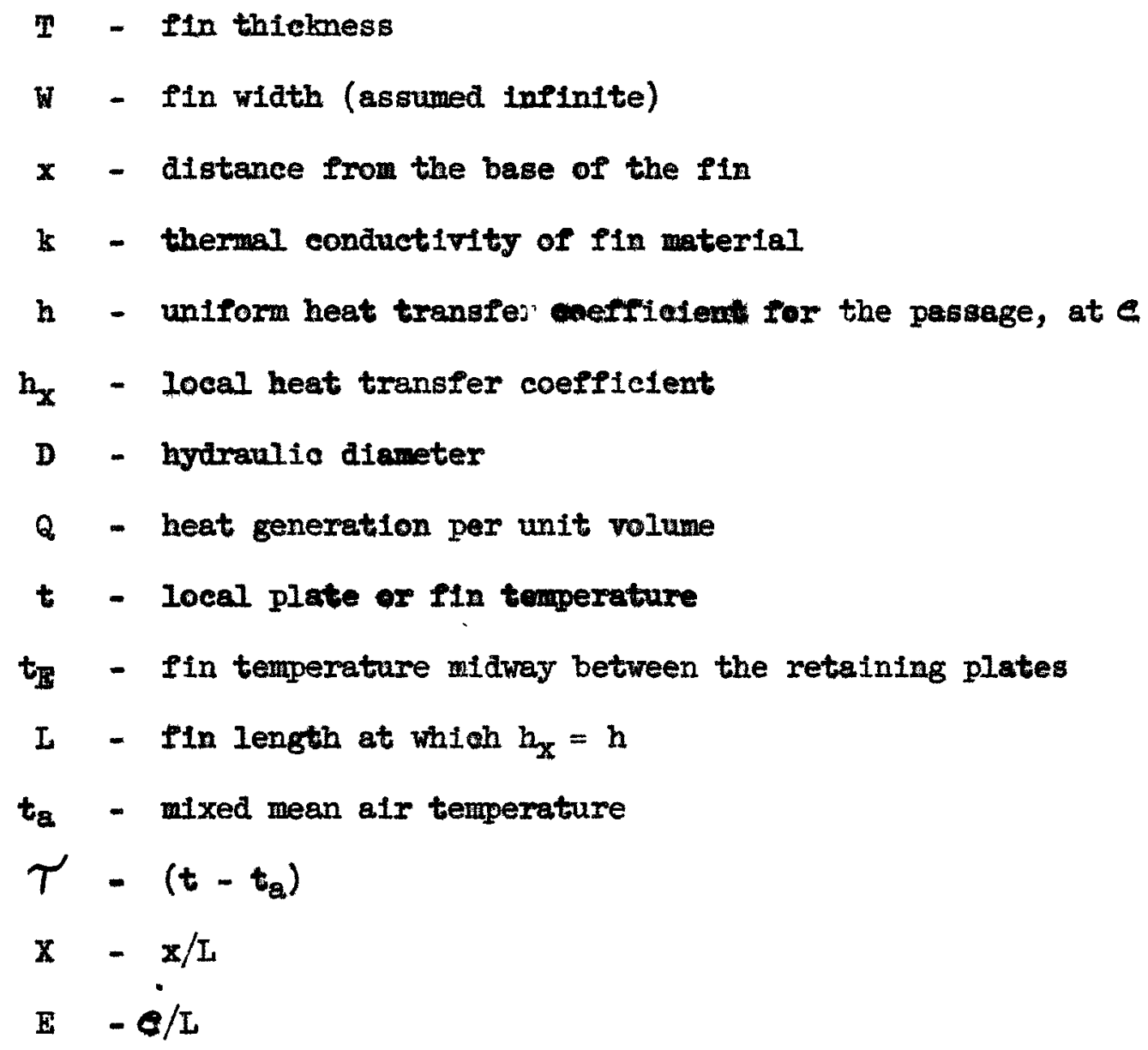

It is necessary to divide the fin into two regions. The first has a varlable heat transfer coeffielent and extends a distance I from the corner. The second extends from $I$ to $e$ and is one over which the heat transfer coefficient is constant. The fin or wall is thin and hence the flor of heat is treated in one dimension. 
$-7-$

Considering the region at the corner first, let us represent our local heat transfer coefficient as a linear function of $x$ for the upper fin surface. Thus:

$$
\mathbf{h}_{\mathbf{x}} / \mathbf{h}=\mathbf{a x}
$$

Similarly for the lower surface

$$
h_{\mathbf{x}} / \mathbf{h}=\mathbf{b x}
$$

A differential equation can be written for the fin by means of a heat balance across the increment $d x$.

(1) Heat into dx, at $x$, by conduction:

$$
q_{1}=-\operatorname{knT}\left(\frac{d t}{d x}\right)
$$

(2) Heat out of $\mathrm{dx}$, at $\mathrm{x}+\mathrm{dx}$, by conduction:

$$
q_{2}=-\operatorname{krr}\left(\frac{a t}{d x}+\frac{a^{2} t}{d x^{2}} d x\right)
$$

(3) Heat lost to the surroundings by convection:

$$
q_{3}=(a h x+b h x)(k T d x)=h h e \tau x d x .
$$

Letting $I=a+b$

(4) Heat generated by internal sores:

$$
q_{4}=Q w a x
$$

Combining the ge heat terms and simplifying we obtain the general differential equation:

$$
\frac{a^{2} t}{d x^{2}}-\frac{2}{k}=\frac{a^{i}}{k}
$$

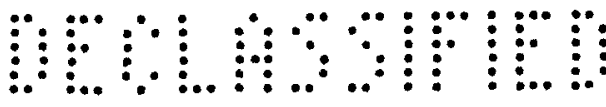


On changing varlables we obtain:

$$
\frac{d^{2} \tau}{d x^{2}}-\frac{h L^{3}}{k r} x \tau=-\frac{Q x^{2}}{x}
$$

Th1s is a linear second order differential equation. The solution of the homogeneous equation can be found by the method of integration by series. Having determined the solution of the homogeneous equation, it is then possible to obtain the partieular solution to the complete differential equation wiad Plcards Iterative mothod. The sum of the homogeneens and particular solution forms the couplete solution as follows:

$$
\begin{aligned}
& \gamma=c_{0}\left(1+\frac{h+t^{3}}{2 \cdot 3}+\left[\frac{x^{3}}{2 \cdot x^{3}}\right]^{2} \frac{x^{6}}{2 \cdot 3 \cdot 5 \cdot 6}+\ldots\right) \\
& +A_{1}\left(x+\frac{h I^{3}}{x^{3}} \frac{x^{4}}{3 \cdot 4}+\left[\frac{m^{3}}{x \cdot 2}\right]^{2} \frac{x^{7}}{3 \cdot 4 \cdot 6 \cdot 7}+\ldots\right)
\end{aligned}
$$

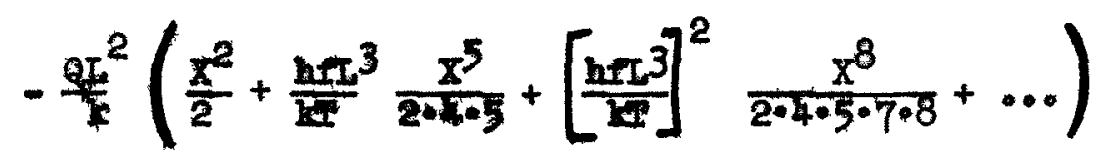

were $A_{0}$ and $L_{1}$ are combente value depends on the boundary conditious.

Let us take for boundary conditions $\tau^{\prime}=\tau_{0}$ and $\frac{d}{d x}=0$ at $x=0$. This

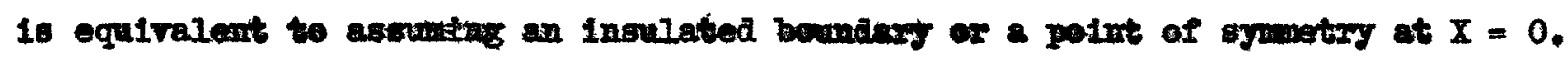
Then $\Lambda_{b}=T$ and $\Lambda_{1}: 0$.

Over the aceond region of wing the heat transfer coefficient is a conmtant value on both surfaces. For this region the differential equation is

$$
\frac{\mathrm{d}^{2} \tau}{\mathrm{d} \mathrm{X}^{2}}-\frac{2 \mathrm{~h}^{2}}{\mathrm{k}} \tau=-\frac{\mathrm{Q} \mathrm{L}^{2}}{\mathrm{k}}
$$


Whis is a scond order Iinear differential equation vith constant coefflelents. The solution is roadily found to be:

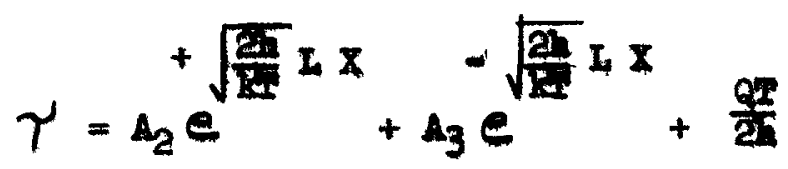

The beandary conditions are given by $\tau=\tau_{E}$ at $X=I$ and that the temperature gradient and tenperature at the junction of the two reglons must be equal. Designating the tempexature at the junction where $X=1$ $(x=I)$, as $\mathcal{T}_{1}$ the arbitrary constants $A_{2}$ and $A_{3}$ above can be evaluated. The rolution then becwuest

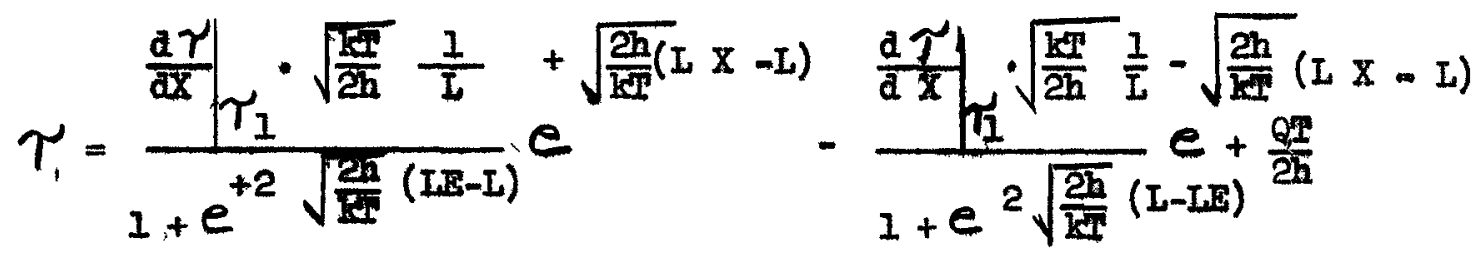

A Bolution for the cormer terperature can now be found by equating temperatures for both reglons at $X=1$ and substituting for the gradient above that dertved from the expression for the region near the cormer.

Thus let us use the solution for the first region for an insulated bage or zero gradient at $x=0$. On equating terperatures for both regens at $x=1$ the following expression eontaining the "hot spot" or corner temperature $\tau_{0}$ results: 


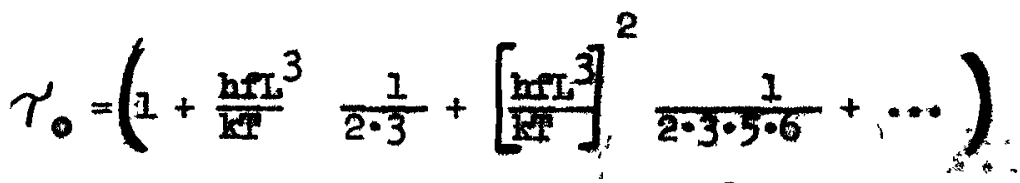

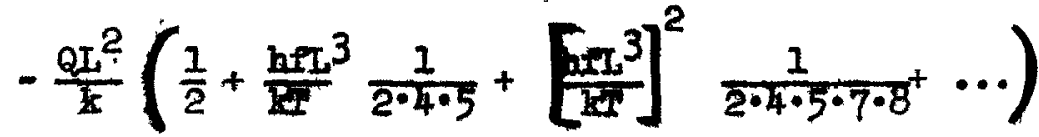

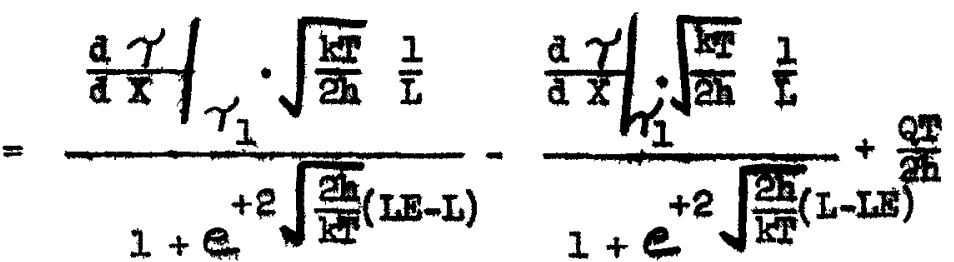

where

$$
\begin{aligned}
& \left.\frac{\mathrm{d} \tau}{\mathrm{d} \alpha}\right|_{1}=\tau_{0}\left(\frac{\mathrm{hr} \mathrm{T}^{3}}{\mathrm{k}} \frac{1}{2}+\left[\frac{\mathrm{heL}}{\mathrm{kT}}\right]^{2} \frac{1}{2 \cdot 3 \cdot 5}+\cdots\right)
\end{aligned}
$$

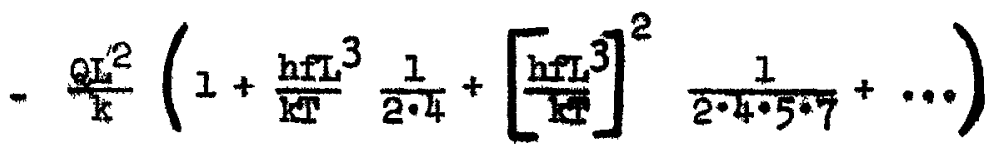

In order to complete our analysis we mat exnalne the vertical mal or retaining plate to ascentain the locel temperature rise due to the Insulating effect of the horizontal wall. We shall treat it as a plate vith en insulated atrip and shape as fellorrs:
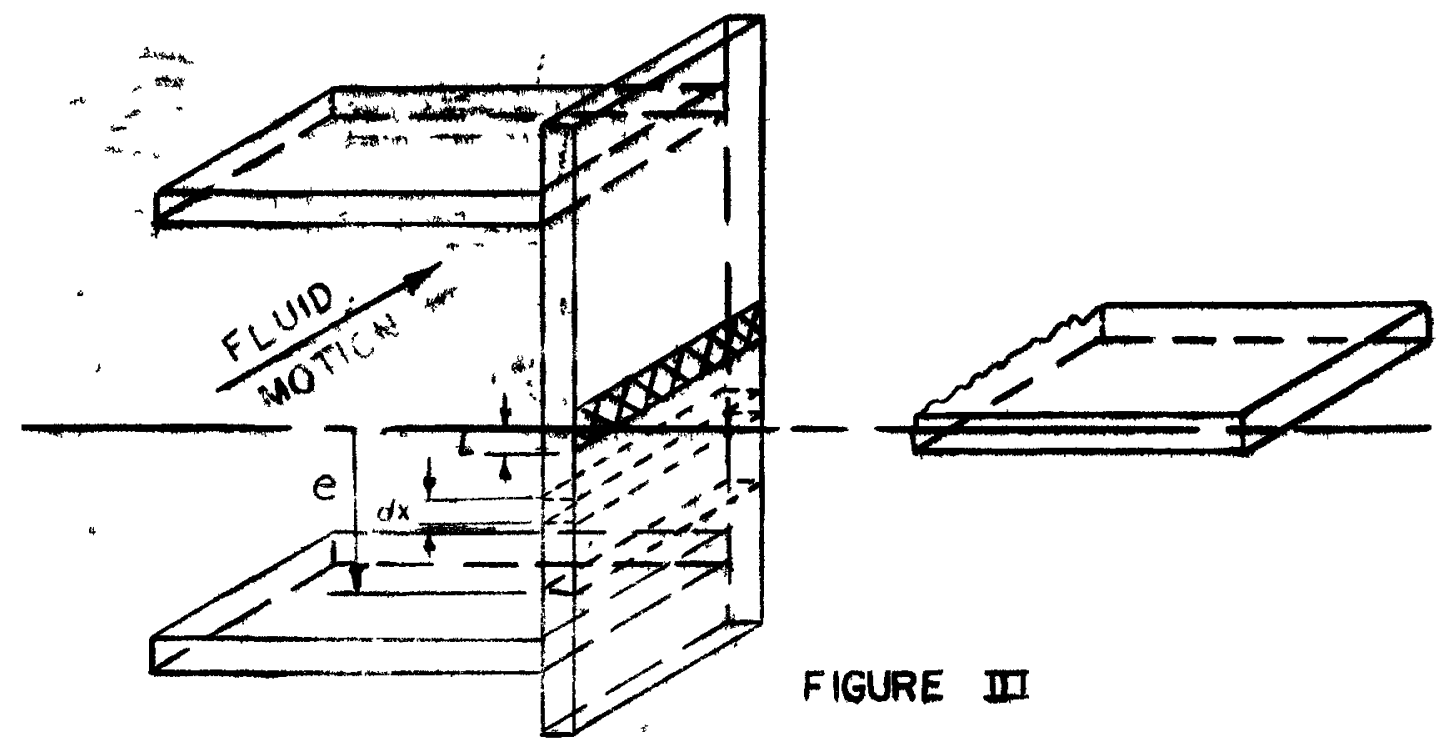

FIGURE III

TWO -REGION FIN, WITH, AN INSULATED STRIP ON

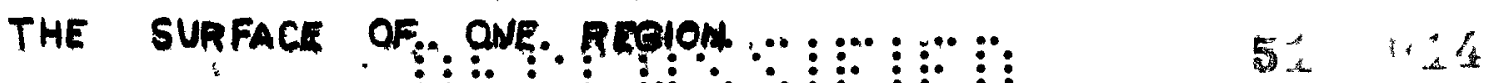


The symbols to be employed have the same designation as in the previous problem. The plate temperature is symetrical about a plane through the midale of the insulated section. Again we must divide the resulting fin below the plane of symmetry into two regions. The first region extends a distance I from the symmetrical temperature plane. Over this region, one side of the plate has a uniform $h$ and the other side is insulated. The second region extends from $L$ to $e$ and the $h$ is uniform on both sides.

The equation giving the wall temperature over the region with a constant heat transfer coefficlent on one side and insulated boundary on the other, is given by:

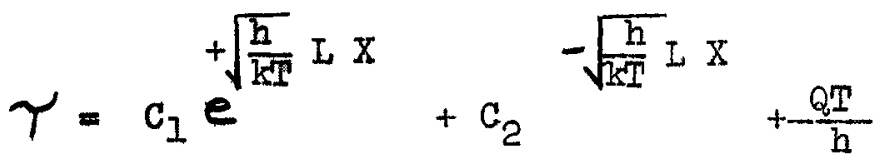

where $C_{1}$ and $C_{2}$ are arbitrary constants. The point $X=0$ has a temperature $\tau_{0}$ and a temperature gradient of 0 . Hence, the constants are evaluated as:

$$
c_{1}=c_{2}=\frac{T_{0}^{\prime}}{2}-\frac{Q T}{2 h}
$$

The wall temperature over the second region in which the heat transfer coefficient is a constant on both sides is given by:

$$
\tau=c_{3} e^{\sqrt{\frac{2 h}{k I}} I x}+c_{4} e^{-\sqrt{\frac{2 h}{k T}} I x}+\frac{\partial T}{2 h}
$$

Again equating temperatures and gradients at the junction of the two regions (at $X=I$ ), using the boundary condition $T=\tau_{\mathbb{I}}$ at $X=E$, we axitre at an expression containing the "hot spot" or comer temperature $\tau_{0}$. 


$$
\begin{aligned}
& \left(\frac{\tau_{0}}{2}-\frac{2 T}{2 h}\right)\left(e^{\sqrt{\frac{h}{k T}} I}+e^{-\sqrt{\frac{h}{k T}}}\right)+\frac{Q T}{2 h}=
\end{aligned}
$$

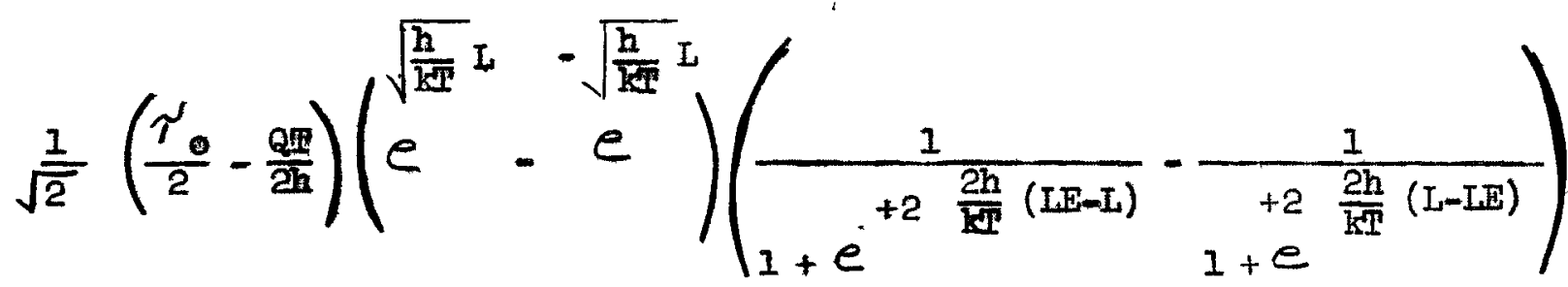

Numerical results are presented for the assembly (See Figure I) listed as first preference.

The junction of the horizontal plate with the retaining plate can be approximated by our two previous fin solutions. The fin to wall angle is taken as $90^{\circ}$ on each side. The physical dimensions and heat transfer properties of the assembly are taken from the above mentioned memo. of the assembly are taken from the above mentioned memo.

$$
\begin{aligned}
& k=15 \mathrm{Bta} / \mathrm{Hr} \text {. Ht. } 2 \text { O F }_{\mathrm{Ft}} \text {. } \\
& Q=329 \times 10^{6} \mathrm{Btu} / \mathrm{hr} . \mathrm{ft}^{3} \text { (at the back of the first row of plates) } \\
& \mathrm{I}=0.001 \text { ft. for the plates } \\
& =0.00125 \text { ft. for the retaining plate } \\
& \mathrm{h}=181 \mathrm{Btu} / \mathrm{hr} . \mathrm{ft} \text {. }^{2} \mathrm{o}_{\mathrm{F}} \\
& t_{\mathrm{a}}=658^{\circ} \mathrm{F} \\
& t_{\mathrm{m}}=1573^{\circ} \mathrm{F} \\
& D=0.0368 \text { ft. } \\
& a=b=638 \text { hence } f=1276
\end{aligned}
$$


Let us consider first a horizontal plate using our first generalized solution for a variable heat transfer coefficient along the surface. For the assembly shown in Figure I, a zero temperature gradient at the fin base or at $\mathrm{X}=\mathrm{O}$ is a satisfactory first assumption. For the assembly shown, $\mathrm{L}=$ $0.001565 \mathrm{ft}$. and $E=42.5$. Substituting the above values into the generalized expression, an expression is obtained containing the "hot spot' temperature $\tau_{0}$.

$$
\begin{gathered}
\tau_{0}\left(1+\frac{0.059}{6}+\ldots\right)-54\left(0.5+\frac{0.059}{40}+\ldots\right)= \\
\left\{\tau_{0}\left(\frac{0.059}{2}+\frac{0.059^{2}}{30}+\cdots\right)-54\left(1+\frac{0.059}{8}+\ldots\right)\right\} \cdot\left\{\frac{1}{0.243}\right\} \\
\left\{\frac{1}{1+e^{311 \times 42.5}}-\frac{1}{\left.1+e^{-311 \times 0.01565 \times 4.25}\right\}+915}\right\}
\end{gathered}
$$

or

$$
\tau_{0}(1.001)-54(0.5015)=-\frac{0.0295 \tau_{0}-1.0074 \times 54}{0.243}+915
$$

Hence

$$
\tau_{0}=1037^{\circ} \mathrm{F}
$$

and

$$
\tau_{0}-\tau_{m}=1037-915=122^{\circ} \mathrm{T} \text { (Hot spot rise) }
$$

Next let us examine the vertical retaining plate for a hot spot at the junction with the plate using our second generalized fin solution for an insulated border. The insulated border can be taken as equal to the sum of the width of a plate and the distance over which $h_{\mathrm{X}}$ is less than $h$. Fence for 
the assenibly shem, $I=0.002065$ It. and $E=32.2$. Subetituting the above values Into the generalized solution for this stuation, the following equation containing the "hot spot" temperature reaults.

$$
\begin{gathered}
\left(\frac{\tau_{0}}{2}-915\right)\left(e^{0.203}+e^{-0.203}\right)+915= \\
\frac{1}{1.415}\left(\frac{\tau_{0}}{2}-915\right)\left(e^{0.203}-e^{-0.203}\right)\left\{\frac{1}{\left.1+e^{0.574 \times 31.2}-\frac{1}{1+e^{-0.574 \times 31.2}}\right\}}\right.
\end{gathered}
$$

or

$$
\left(\frac{\tau_{0}}{2}-915\right) 2.040+915=-\left(\frac{\tau_{x}=0}{2}-915\right) \frac{0.410}{1.415}
$$

Hence

$$
\tau_{0}=1044^{\circ} \mathrm{F}
$$

and

$$
\tau_{0}-\tau_{m}=1044-915=129^{\circ} \mathrm{F} \text { (Hot spot rise) }
$$

Since both temperatures $\left(\tau_{0}\right)$ are approximately the same, the assumption that the base of the pulte is inswiated is satisfactory.

\section{DISCUSSION}

The preceding analysis has been made in a general fashion to facilitate computations on various design proposals for the assembly. The equations are applicable to other primary to retaining plate angles besides the $90^{\circ}$ angle used in the numerical calculation above. It is interesting to note that a change from $90^{\circ}$ to $60^{\circ}$ on both sides of the primary plate in our previous problem would increase the "hot spot" temperature rise from 1250F to approxi- 
mately $250^{\circ} \mathrm{F}$. Hence, it is desirable to keep angles between plates as large as possible.

If in our first generalized solution the base of the IIn is not instulated, then $A_{I}$ is not zero. Expressing the temperature gradient at $X=0$ by $\frac{d \tau}{d X}=-\frac{Q L}{T W W}$, then $A_{I}=-\frac{Q L}{T w d}=\frac{d \tau}{d X} \tau_{0} \cdot$ In most problems the corner will be point of symetry for the temperature pattern and hence the temperature gradient at that point will be zero and consequently $A_{1}$ will be zero. We have also assumed the mfdpoint temperature to be the average temperature. Since the local temperature rise oecurs only in that small part of the plate at the cormer this assumption is sufficiently accurate for computational parposes.

When the included angle between the primary plate and adjacent plate or retaining plate is different on both sides, then the first genexalized analysis will involve a three region solution. The method to be employed vill however be identical to that for the two region problem presented herein. 